OPEN ACCESS

Edited by:

Giancarlo Castaman

University of Florence, Italy

Reviewed by:

Hamideh Yadegari Baharanchi, University Hospital Bonn, Germany

Augusto B. Federici,

University of Milan, Italy

*Correspondence:

Bipin P. Kulkarn

kulkarni.bipin@gmail.com orcid.org/0000-0002-5341-5256

Specialty section: This article was submitted to Hematology,

section of the journa

Frontiers in Medicine

Received: 02 November 2021 Accepted: 13 December 2021

Published: 11 January 2022

Citation:

Kulkarni BP, Ghargi K, Shanmukhaiah $C$ and Shetty $S D$ (2022) Rare Occurrence of Inhibitors in Von Willebrand Disease: A Case Report. Front. Med. 8:807664. doi: 10.3389/fmed.2021.807664

\section{Rare Occurrence of Inhibitors in Von Willebrand Disease: A Case Report}

\author{
Bipin P. Kulkarni ${ }^{1 *}$, Kirti Ghargi ${ }^{1}$, Chandrakala Shanmukhaiah ${ }^{2}$ and Shrimati D. Shetty ${ }^{1}$ \\ ${ }^{1}$ ICMR- National Institute of Immunohaematology, KEM Hospital Campus, Mumbai, India, ${ }^{2}$ Department of Haematology, \\ KEM Hospital, Mumbai, India
}

Introduction: Type 3 Von Willebrand Disease (VWD) is the least common but the most severe form of a disease, with a prevalence of about 0.5 to 1 per million in Western countries. The prevalence of type 3 WWD in the developing countries, with a high degree of consanguinity, is about 6 per million. Moreover, due to underdiagnosis of the milder cases, the prevalence of type 3 WWD is about $50 \%$ of the cases. Rarely, some patients develop the Von Willebrand Factor (VWF) inhibitors, which may subsequently develop severe anaphylactic reactions on further exposure to the WWF containing factor replacement therapy. The prevalence of inhibitor development in patients with type 3 WWD has been shown to be in the range of 5.8 to $9.5 \%$. In the absence of a gold standard assay for the quantitation of WWF inhibitors, a correct diagnosis and management of these patients are often challenging.

Objectives: The objective of this study is to standardize the Bethesda assay for the VWF inhibitors and to estimate the VWD inhibitor titer in two cases of congenital type 3 WWD, which developed the WWF inhibitors.

Results and Conclusions: We could successfully standardize the Bethesda assay for the quantitation of WWF inhibitors in two patients with congenital type 3 VWD with inhibitors.

\section{Keywords: VWD, inhibitors, quantitation, Bethesda assay, rare occurrence}

\section{CASE 1}

A 5-year-old female child has a known case of congenital type 3 VWD, born of consanguineous marriage, and with a homozygous deletion of whole VWF gene, as shown by NGS- exome sequencing. She presented with a history of fall, hurting the left side of her jaw, and developed a painful swelling of the left jaw with gradual extension, resulting in severe pain. On clinical examination, she showed swelling, which was tender and warm, extending from the body of mandible to an angle measuring approximately $3 \times 4 \mathrm{~cm}$. She was treated with Intermediate Purity Factor (IPF) VIII concentrate (Immunate, 2:1 ratio of FVIII and VWF; Koate, 1:1 ratio of FVIII and VWF) at $20 \mathrm{IU} / \mathrm{kg}$ twice weekly for 2 weeks. However, the swelling and pain started worsening, as well as the intermittent gum bleeding. The duration of infusion was increased to thrice a week. The patient did not show progress and she continued to have gum bleeding. She was posted for curettage of the pseudo tumor. She developed itching and has rashes all over body. Due to the sub-optimal response to treatment and to allergic reaction, the presence of the VWF inhibitors was suspected. 


\section{CASE 2}

A 25-year-old woman phenotypically diagnosed at the age of 5 years old, has a congenital type $3 \mathrm{VWD}$, was born to a 2nd degree consanguineous parents, presented with recurrent episodes of ecchymosis, heavy menorrhagia, and melena. She had multiple episodes of severe melena and was presented with shock. On infusion of IPF (Immunate, 2:1 ratio of FVIII and VWF) at 20 IU/kg twice weekly for 2 weeks, there was no response. She had 50 days of exposure to the IPF. She was referred to this center with the suspected VWF inhibitors.

\section{LABORATORY INVESTIGATIONS Screening for VWF Inhibitors}

The baseline screening coagulation assays, APTT mixing, Von Willebrand Factor: Antigen (VWF:Ag), Von Willebrand Factor: Ristocetin Cofactor (VWF:RCo), and Factor VIII: Clotting (FVIII:C) assays were performed on the plasma samples of the patients, alongside normal pooled plasma (NPP) (Table 1). Another known inhibitor, the patients with the negative type 3 VWD plasma with VWF: Ag level of $1.8 \%$, was tested alongside as test control. The plasma of the patients and the test control plasma were separately mixed with an NPP, in a 1:1 dilution $(150 \mu \mathrm{l}$ pt./test control plasma $+150 \mu \mathrm{l}$ of NPP) and incubated at $37^{\circ} \mathrm{C}$ for $1 \mathrm{~h}$. After incubation, the VWF: Ag levels and the VWF:RCo activity were assayed on an ACL TOP 300 automated coagulation analyzer (Instrumentation Laboratory, Lexington, MA, USA) (Table 2).

\section{VWF Inhibitor Assay}

There is no gold standard assay for the identification and quantification of VWF inhibitors. Hence, the approach taken was based on the principle of combining the studies, followed by the Bethesda assay, to estimate the VWF inhibitors (1). The inhibitor titer was then derived from the Bethesda graph, based on the residual VWF:RCo activity.

TABLE 1 | Baseline screening coagulation, APTT mixing, WWF:Ag, WWF:RCo, and FVIII:C assays performed on NPP and on plasma samples of the patients.

\begin{tabular}{lccc}
\hline Parameters & Normal pooled plasma (NPP) control & Case 1 & Case 2 \\
\hline PT & $13.7 \mathrm{~s}$ & $15.5 \mathrm{~s}$ & $14.4 \mathrm{~s}$ \\
APTT & $26.6 \mathrm{~s}$ & $47 \mathrm{~s}$ & $45 \mathrm{~s}$ \\
APTT mixing & - & $38.7 \mathrm{~s}$ & $30.8 \mathrm{~s}$ \\
WWF: Ag & $113.10 \%$ & $<2.2 \%$ & $<2.2 \%$ \\
WWF:RCo & $111.40 \%$ & $1.60 \%$ & $2.40 \%$ \\
Factor VIII & $152 \%$ & $1.80 \%$ & $2.60 \%$ \\
\hline
\end{tabular}

TABLE 2 | Mixing studies.

\begin{tabular}{lccc}
\hline & Test control + NPP & Case 1 + NPP & Case 2 + NPP \\
\hline WW:Ag & $54.8 \%$ & $<2.2 \%$ & $24.6 \%$ \\
WWF:RCo & $52.4 \%$ & $0.0 \%$ & $0.0 \%$
\end{tabular}

The plasma samples of the patients were serially diluted using the Owren Koller (OK) buffer. Each of the dilution was mixed with an equal volume of NPP. A Buffer Blank, containing NPP and $\mathrm{OK}$ buffer, was taken as a reference control. The serially diluted plasma of the patients and the reference control reactions were incubated at $37^{\circ} \mathrm{C}$ for $2 \mathrm{~h}$. After incubation, the reference control and the serial dilutions of the patients' plasma were diluted to obtain 1:5 and 1:10 dilutions with OK buffer. The VWF:RCo activity in control dilutions was determined using a ACL-VWF:RCo kit (Instrumentation Laboratory Company Lexington, MA 02421-3125, USA), and was compared with each of the serial dilutions of the patients' plasma (Table 3 ).

The detailed protocol is as given below:

1. The plasma samples of the patients were incubated at $56^{\circ} \mathrm{C}$ for $30 \mathrm{~min}$ to eliminate any residual VWF by heat inactivation, whereas the antibodies are heat resistant. The plasma of the patients were then centrifuged at 4,000 rpm for $15 \mathrm{~min}$ and the supernatant plasma, containing the VWF inhibitors, was harvested for testing, leaving out the heat-coagulated pellet of the plasma proteins.

2. The plasma of the patients obtained through step 1 was serially diluted with $\mathrm{OK}$ buffer to dilutions of 1:2, 1:4, and up to 1:256, to serially dilute the VWF inhibitors that were present in the patients' plasma.

3. Each dilution was mixed with NPP in 1:1 proportion in siliconized glass tubes.

4. The NPP, with OK buffer in 1:1 proportion, was taken as a reference control.

5. All tubes in points 3 and 4 above were incubated at $37^{\circ} \mathrm{C}$ for $2 \mathrm{~h}$.

6. After incubation, 1:5 and 1:10 dilutions were made from each tube with OK buffer.

7. The VWF:RCo activity was determined in each dilution on ACL TOP 300 automated coagulation analyzer (Instrumentation Laboratory, Lexington, MA, USA), and the results were recorded and analyzed as explained in the section below.

Table 2 shows 50\% correction in the test control VWF:Ag and VWF:RCo levels, suggesting the absence of VWF inhibitors in the test control plasma of the patients. However, the patients with possible VWF inhibitors showed no correction in VWF:RCo

TABLE 3 | Residual WWF:RCo as determined by the nearest dilution factor of 1:5 dilution of the patient, to the 1:10 dilution of the reference control.

\begin{tabular}{|c|c|c|c|c|}
\hline \multirow[b]{2}{*}{ Assay dilutions } & \multicolumn{2}{|c|}{$\begin{array}{c}\text { Case } 1 \\
\text { VWF:RCo (\%) }\end{array}$} & \multicolumn{2}{|c|}{$\begin{array}{c}\text { Case } 2 \\
\text { VWF:RCo (\%) }\end{array}$} \\
\hline & $1: 5$ & $1: 10$ & $1: 5$ & $1: 10$ \\
\hline OK + NPP (Reference control) & 17.5 & 8.0 & 18.3 & 8.7 \\
\hline Patient plasma 1:2 dilution & 0.0 & - & 0.0 & \\
\hline Patient plasma 1:4 dilution & 0.0 & - & 7.5 & 3.0 \\
\hline Patient plasma 1:8 dilution & 0.0 & - & 14.2 & 6.7 \\
\hline Patient plasma 1:64 dilution & 0.0 & - & - & - \\
\hline Patient plasma 1:128 dilution & 5.4 & 2.4 & - & - \\
\hline Patient plasma 1:256 dilution & 13.0 & 6.1 & - & - \\
\hline
\end{tabular}


levels. However, in case 2, the VWF:Ag was not completely inhibited. This indicated the presence of VWF inhibitors in the plasma of the patients, more so against the VWF:RCo activity, possibly because of the effect of inhibitors on large multimers. Both the patients were negative for FVIII:C inhibitors.

From Table 3, it was observed that in Case 1, the VWF inhibitor titer was between the residual VWF:RCo \% activity corresponding to the dilution factors of 1:128 and 1:256; while in Case 2, the inhibitor titer was between the dilution factors of $1: 4$ and $1: 8$.

\section{The Bethesda Assay}

One Bethesda unit is defined as the concentration of inhibitors that neutralize $50 \%$ of the factors in NPP/reference plasma.

In the FVIII inhibitor Bethesda assay, which is a clot-based assay, the clotting time of the patients' plasma decreases as we go higher with inhibitor dilutions, to a point where the 1:5 dilution clotting time of the patients is the closest to the 1:10 dilution clotting time of the reference controls. The residual FVIII:C value is then obtained from the factor assay graph and is plotted on the Bethesda graph to obtain the corresponding $\mathrm{Bu} / \mathrm{ml}$, which is multiplied with the dilution factor to obtain the final $\mathrm{Bu} / \mathrm{ml}$ titer.

As per Bethesda assay principle, the 1:10 dilution corresponds to 50\% VWF:RCo activity value. In Table 3, Case 1: Reference Control, the $1: 10$ dilution value of $8 \%$ corresponds to $50 \%$. Therefore, the patient's value of $5.4 \%$ corresponds to $50 \times 5.4$ / $8=33.75 \%$ (residual VWF:RCo activity), and has obtained the corresponding $\mathrm{Bu} / \mathrm{ml}$ value of 1.7 from the graph (Figure 1). The $1.7 \mathrm{x}$ dilution factor of $128=217.6 \mathrm{Bu} / \mathrm{ml}$ was the VWF:RCo inhibitor Bethesda level of the Case 1.

Similarly, in Case 2: Reference Control, the 1:10 dilution value of $8.7 \%$ corresponds to $50 \%$. Therefore, the patient's value of $7.5 \%$ corresponds to $50 \times 7.5 / 8.7=43.10 \%$ (residual VWF:RCo activity), and has obtained the corresponding $\mathrm{Bu} / \mathrm{ml}$ value of 1.2 from the graph (Figure 1). The $1.2 \mathrm{x}$ dilution factor of $4=4.8$ $\mathrm{Bu} / \mathrm{ml}$ was the VWF:RCo inhibitor Bethesda level of the Case 2.

\section{DISCUSSION}

Development of inhibitors to a VWF in a congenital type 3 VWD patient, followed by either recombinant or intermediate purity of the VWF containing Factor VIII concentrate, is a rare incidence. Due to underdiagnosis of the milder cases, the prevalence of type 3 VWD is about $50 \%$ of the cases (2-4). Rarely, some patients develop the Von Willebrand Factor (VWF) inhibitors, which may subsequently develop severe anaphylactic reactions on further exposure to the VWF containing factor replacement therapy $(5,6)$. The prevalence of inhibitor development in patients with type 3 VWD has been shown to be in the range of 5.8 to $9.5 \%$ (7-12).

The first case of a severe type 3 VWD with inhibitors was reported in 1974 (13). Subsequently, more studies on type 3 VWD with inhibitors were reported (14). A recently large study on 99 Iranian patients with type 3 VWD reported $19.2 \%$ positivity for VWF inhibitors, which is substantially higher than the earlier reports (15). Most of the reports of VWF inhibitors were from patients with partial or complete VWF gene deletions.
However, subsequent publications have reported patients with non-sense, frameshift mutations, and partial or complete gene deletions. Moreover, not all cases of partial gene deletions develop alloantibodies against VWF, which was described in a study of 25 patients with type 3 VWD cases, of which, five had homozygous partial large deletions, and yet did not develop VWF inhibitors as a complication to treatment (1).

Once a patient develops the inhibitor, any further exposure to VWF can give rise to severe anaphylactic reactions (1). Moreover, there is no standardized assay available for the reliable detection and quantitation of the VWF inhibitors. This can potentially cause delays before the laboratory diagnosis of the VWD inhibitors is made, jeopardizing the treatment of the patients who were bleeding and posing a life-threatening situation. The available assays are based on the principle of combined studies to demonstrate the inhibition of the plateletdependent function of VWF. It has been recommended to broadly evaluate the VWF function. Some laboratories have used an enzyme-linked immunosorbent assay (ELISA). These assays appear to be sensitive, however, there is a concern about their high rate of false positivity $(1,16-18)$. The mixing studies with NPP as control, followed by a Bethesda assay, correlated well with the inhibitor titres, as reflected in the clinical outcomes of the patients. After the VWF inhibitor assays, the Case 1 has underwent a surgery for her pseudotumor and was given rFVIIa (90 mcg/kg body weight) just prior to surgery. After $30 \mathrm{~min}$ of starting the surgery, she had an uncontrolled bleeding from the wound and again was started on of rFVIIa $(90 \mathrm{mcg} / \mathrm{kg}$ body weight). On day 3 , she had a persistent swelling of the jaw and her platelet count had dropped to $10 \times 10^{9} / \mathrm{L}$. In view of the severe thrombocytopenia, IVIG ( $1 \mathrm{~g} / \mathrm{kg}$ body weight) was given, along with methylprednisolone. Platelet count increased to $75 \times 10^{9} / \mathrm{L}$. As her response to rFVIIa was unsatisfactory, she was treated with rituximab $375 \mathrm{mg} / \mathrm{m}^{2}$ weekly, once a week for 4 weeks. Though there was reduction in bleeding, she still continued to have swelling on her jaw. She was then started on emicizumab ( $3 \mathrm{mg} / \mathrm{kg}$ body weight) once a week for 1 month followed by once in 2 weeks. She was given 4 doses of emicizumab, after which, her swelling subsided completely. She completed 16 weeks of treatment and she did not have any breakthrough bleeding, neither required for blood nor Clotting Factor Concentrate (CFC) support.

The second patient was treated with rFVIIa + rFVIII. Both the patients responded well to the treatment and recovered.

Some of the treatment modalities successfully used are rFVIII, rFVIIa, rFVIIa, and rFVIII, Platelet infusions, APCC, Antifibrinolytics, and even Immune Tolerance Induction (ITI) have been successfully attempted with VWF/F8 Conc. and IVIG with Corticosteroids (1).

The effect of alloantibodies on the functionality of VWF needs to be studied, as the antibodies may have different epitope specificities on the VWF molecule. A regular inhibitor screening in patients with type $3 \mathrm{VWD}$ on requiring frequent infusions may be considered.

The limitation of this assay is that we could not compare and validate the VWF inhibitor titer with a gold standard assay. Also, a negative result does not rule out VWF inhibitors. The inhibitors 


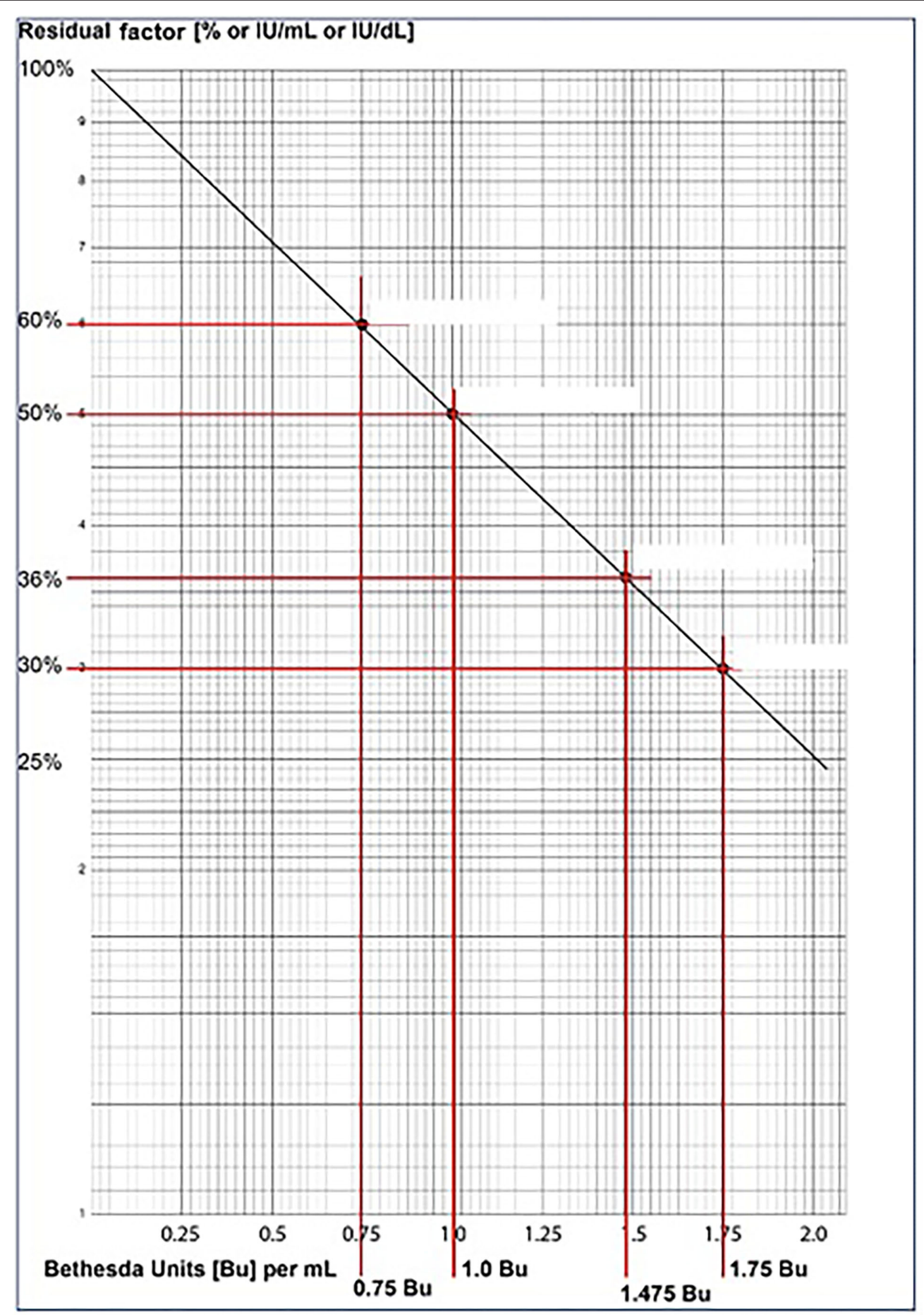

FIGURE 1 | Shows a representative Bethesda assay graph for plotting the calculated residual VWF:RCo \% activity, to derive the inhibitor titer in Bu/ml, which is then multiplied with the dilution factor to obtain the final VWF inhibitor titer in Bu/ml. 
could be directed to other functional or non- functional domains of the VWF. Hence, VWF: Collagen Binding (VWF:CB) assay is also recommended (1). However, the standardized assay is robust, reproducible, and the inhibitor titer correlates well with the clinical manifestations of the patients.

\section{CONCLUSION}

Inhibitors to VWF in type 3 VWD patients is not a common occurrence. We have not only identified 2 such patients of type 3 VWD who developed inhibitors, but also could reliably estimate the inhibitor titer by adapting the Bethesda assay for VWF inhibitors, which we have described in detail.

\section{DATA AVAILABILITY STATEMENT}

The original contributions presented in the study are included in the article/supplementary material, further inquiries can be directed to the corresponding author/s.

\section{REFERENCES}

1. James PD, Lillicrap D, Mannucci PM. Alloantibodies in von Willebrand disease. Blood. (2013) 122:636-40. doi: 10.1182/blood-2012-10-462085

2. Trasi S, Shetty S, Ghosh K, Mohanty D. Prevalence and spectrum of von Willebrand disease from western India. Indian J Med Res. (2005) 121:653-8.

3. Srivastava A, Rodeghiero F. Epidemiology of von Willebrand disease in developing countries. Semin Thromb Hemost. (2005) 31:569-76. doi: 10.1055/s-2005-922229

4. Elayaperumal S, Fouzia NA, Biswas A, Nair SC, Viswabandya A, George B, et al. Type-3 von Willebrand disease in India-Clinical spectrum and molecular profile. Haemophilia. (2018) 24:930-40. doi: 10.1111/hae.13542

5. Bergamaschini L, Mannucci P, Augusto B, federici AB, Coppola P, et al. Post transfusion anaphylactic reactions in a patient with severe Von Willebrand disease: Role of complement and alloantibodies to von Willebran factor. J Lab Clin Med. (1995) 125:348-355.

6. Franchini M, Gandini G, Guiffrida A, DE Gironcoli M, Federici AB. Treatment of a patient with type 3 VWD and alloantibodies; a case report. Hemophilia. (2008) 14:645-646. doi: 10.1111/j.1365-2516.2008.01668.x

7. Hassan MY, Robert C, Jessica M, Walid KS, George R, Rodgers $\mathrm{GM}$, et al. Inhibitors to Von Willebrand Factor in Type 3 Von Willebrand Disease (VWD). Biomed J Sci \& Tech Res. (2017) 1:552-5. doi: 10.26717/BJSTR.2017.01.000242

8. Stratton RD, Wagner RH, Webster WP, Brinkhous KM. Antibody nature of circulating inhibitor of plasma von Willebrand factor. Proc Natl Acad Sci USA. (1975) 72:4167-71. doi: 10.1073/pnas.72.10.4167

9. Mannucci PM, Meyer D, Ruggeri ZM, Koutts J, Ciavarella N, Lavergne JM. Precipitating antibodies in von Willebrand's disease. Nature. (1976) 262:1412. doi: $10.1038 / 262141 \mathrm{a} 0$

10. Mannucci PM, Mari D. Antibodies to factor VIII-von Willebrand factor in congenital and acquired von Willebrand's disease. Prog Clin Biol Res. (1984) 150:109-22.

11. Mannucci PM, Federici AB. Antibodies to von Willebrand factor in von Willebrand disease. Adv Exp Med Biol. (1995) 386:87-92. doi: 10.1007/978-1-4613-0331-2_7

12. Iorio A, Oliovecchio E, Morfini M, Mannucci PM, Association of Italian Hemophilia Centres Director. Association of Italian hemophilia centres directors. Italian Registry of Haemophilia and allied disorders objectives, methodology and data analysis. Haemophilia. (2008) 14:444-53. doi: 10.1111/j.1365-2516.2008.01679.x

\section{ETHICS STATEMENT}

The studies involving human participants were reviewed and approved by ICMR- NIIH IEC, ICMR- National Institute of Immunohaematology. Written informed consent to participate in this study was provided by the participants' legal guardian/next of kin.

\section{AUTHOR CONTRIBUTIONS}

BK analyzed the data and wrote the manuscript. KG performed the laboratory assays. CS recruited and treated the patients. SS gave expert inputs and analyzed the data. All authors contributed to the article and approved the submitted version.

\section{ACKNOWLEDGMENTS}

The authors are thankful to the ICMR-NIIH for supporting this study.

13. Sarji KE, Stratton RD, Wagner RH, Brinkhous KM. Nature of von Willebrand factor. A new assay and a specific inhibitor. Proc. nat. Acad. Sci. (1974) 71:2937. doi: 10.1073/pnas.71.8.2937

14. Mannucci PM, Cattaneo M. Alloantibodies in congenital von Willebrand's disease. Ric Clin Lab. (1991) 21:119-25. doi: 10.1007/BF029 19121

15. Jazebi M, Baghaipour MR, Bahoush GR, Ala F, Dorgalaleh A, Moazezi Nekoei Asl SS, et al. Inhibitor development in patients with type 3 Von Willebrand disease, a comprehensive study on 99 Iranian patients. Haemophilia. (2021) 27:520-e524. doi: 10.1111/hae.14266

16. Tiede A, Priesack J, Werwitzke S, Bohlmann K, Oortwijn B, Lenting $P$, et al. Diagnostic workup of patients with acquired von Willebrand syndrome: a retrospective single-centre cohort study. J Thromb Haemost. (2008) 6:569-76. doi: 10.1111/j.1538-7836.2008. 02909.x

17. Stewart MW, Etches WS, Shaw AR, Gordoon PA. VWF inhibitor detection by competitive ELISA. J Immunol Methods. (1997) 200:113-9. doi: 10.1016/S0022-1759(96)00209-8

18. Siaka C, Rugeri L, Caron C, Goudemand J. A new ELISA assay for diagnosis of acquired von Willebrand syndrome. Haemophilia. (2003) 9:3038. doi: 10.1046/j.1365-2516.2003.00750.x

Conflict of Interest: The authors declare that the research was conducted in the absence of any commercial or financial relationships that could be construed as a potential conflict of interest.

Publisher's Note: All claims expressed in this article are solely those of the authors and do not necessarily represent those of their affiliated organizations, or those of the publisher, the editors and the reviewers. Any product that may be evaluated in this article, or claim that may be made by its manufacturer, is not guaranteed or endorsed by the publisher.

Copyright (c) 2022 Kulkarni, Ghargi, Shanmukhaiah and Shetty. This is an openaccess article distributed under the terms of the Creative Commons Attribution License (CC BY). The use, distribution or reproduction in other forums is permitted, provided the original author(s) and the copyright owner(s) are credited and that the original publication in this journal is cited, in accordance with accepted academic practice. No use, distribution or reproduction is permitted which does not comply with these terms. 